\title{
Optimization of Dosage Regimen of Gentamicin against Pasteurella multocida in Bovines: Old Drug, New Approach \\ Pritam Kaur Sidhu' ${ }^{1 *}$, Gurpreet Kaur ${ }^{2}$, Ganesh Kumbhar', Balaje RM ${ }^{3}$ and Mohinder Partap Gupta ${ }^{1}$
}

${ }^{1}$ Animal Disease Research Centre, College of Veterinary Science, Guru Angad Dev Veterinary and Animal Sciences University, India

${ }^{2}$ Department of Veterinary Microbiology, College of Veterinary Science, Guru Angad Dev Veterinary and Animal Sciences University, India

${ }^{3}$ Department of Veterinary Pharmacology and Toxicology, College of Veterinary Science, Guru Angad Dev Veterinary and Animal Sciences University, India

\begin{abstract}
Background: Gentamicin is commonly used to treat Haemorrhagic Septicemia (HS) and other respiratory tract infections in bovines. But no data on its doses and schedules optimized for therapeutic success against $P$. multocida using pharmacokinetics (PK) - pharmacodynamic (PD) integration and modeling is available in farm animals. We investigated PD of gentamicin against $P$. multocida isolates and optimized the dosage schedules in buffalo species using novel approach of PK-PD modeling.
\end{abstract}

Results: The minimum inhibitory concentrations (MICs) and minimum bactericidal concentrations (MBCs) of gentamicin against $P$. multocida in Mueller Hinton Broth (MHB) and serum were similar. The MBC:MIC ratios were 1.23 and 1.27, respectively, for MHB and calf serum.. The mutant prevention concentration (MPC) $=6 \mu \mathrm{g} / \mathrm{mL}$ of gentamicin was higher than MIC $(0.75 \mu \mathrm{g} / \mathrm{mL})$ and $\mathrm{MBC}(0.95 \mu \mathrm{g} / \mathrm{mL})$. In vitro growth inhibition curves of gentamicin in MHB and serum were characteristic of bactericidal activity against $P$. multocida. Time kill kinetics demonstrated that killing activity of gentamicin is concentration andtime dependent.. The values of PK-PD indicators, $C_{\max } / \mathrm{MIC}$ and $\mathrm{AUC}_{24 \mathrm{~h}} / \mathrm{MIC}$ were 21 and $61 \mathrm{~h}$, respectively. Based on MPC, PK-PD indices, $\mathrm{C}_{\max } / \mathrm{MPC}$ and AUC $\mathrm{C}_{24 \mathrm{~h}} / \mathrm{MPC}^{\mathrm{m}}$ were 2.60 and $7.62 \mathrm{~h}$, respectively. Using PK-PD modelling, the predicted gentamicin values of $A U C_{24} / \mathrm{MIC}^{24 \mathrm{~h}}$ for bacteriostatic bactericidal action and bacterial eradication were $32.13,47.15$ and $60.96 \mathrm{~h}$, respectively.

Conclusions: The PK-PD indicespredicted therapeutic success of the gentamicin against $P$. multocida. Based on PK-PD modeling, optimum daily dosage of gentamicin was $2-2.5 \mathrm{mg} / \mathrm{kg}$ for treating infections caused by $P$. multocida $\left(\mathrm{MIC}_{90} \leq 1.0 \mu \mathrm{g} / \mathrm{mL}\right.$ ) in buffalo calves. However, in difficult clinical infections associated with pathogens of $\mathrm{MIC}_{90} \leq 4.0 \mu \mathrm{g} / \mathrm{mL}$, a higher dosage of $7.5 \mathrm{mg} / \mathrm{kg}$ is recommended. Low MPC of gentamicin against $P$. multocida suggested low selection pressure for emergence and amplification of resistant subpopulation during treatment.

Keywords: Gentamicin; Pasteurella multocida; Time-kill kinetics; Mutant Prevention Concentration; PK-PD integration; PK-PD modeling

\section{Background}

The development of antimicrobial resistance from the extensive use of antimicrobial agents and a decline in the development of new agents is threatening human and animal health, and once again infections are becoming untreatable due to emergence of multidrug resistant bacteria. Appropriate use of antibiotics is advocated because there is strong evidence that the dose administered of an antimicrobial to an animal can influence the likelihood of emergence of resistance [1-3]. Therefore, designing optimal dosage schedules of antimicrobials is critical to achieve therapeutic success and prevention of emergence of resistance. For this a comprehensive study on pharmacokinetics (PK) and pharmacodynamics (PD) of antimicrobials in target species is recommended $[4,5]$. Pharmacokinetic models describe the relationship between the dose of a drug and resulting concentrations at different sites of the body. Pharmacodynamic models describe the relationship between drug concentrations in plasma/serum or tissues and resulting therapeutic effect. Improving dosing strategies for antimicrobial drugs that are already clinically available is an effort to increase the life span of antibacterial drugs to treat the infectious diseases. PK-PD modeling provides a quantitative description of the time course of drug disposition and drug effects and dose optimization of antimicrobial agents by this method had been suggested by various workers [5-7].

The Haemorrhagic Septicaemia (HS) caused by Pasteurella (P.) multocida is of great socio-economic importance across South and Southeast Asia, Africa and many other regions of the world. It is an acute and fatal disease primarily occurring in cattle, water buffaloes and camels, and occasionally in other domesticated and wild mammals [8]. In Asia, buffalo is the most important dairy animal as $95 \%$ of milk produced is from buffaloes. The HS results in severe economic losses and is ranked as the most important contagious disease of cattle and buffaloes with young animals being most at risk of successive outbreaks $[8,9]$. Gentamicin, a broad spectrum aminoglycoside has been widely used for the therapy of serious respiratory tract infections including HS associated with Mannheimia haemolytica and P. multocida in buffaloes, cattle, goats, pigs, sheep, and rabbits. Gentamicin has a narrow therapeutic index (minor difference between toxic and therapeutic blood concentration). Despite the risk of toxicity development, it has the advantage of high clinical efficacy in serious infections and low cost compared to newer agents licensed to use in veterinary medicine. Therefore, the importance of dose optimization of gentamicin for therapy in target (buffalo) species cannot be overlooked. Gentamicin

*Corresponding author: Pritam Kaur Sidhu, College of Veterinary Science Guru Angad Dev Veterinary and Animal Sciences, University, India, Tel: +91-161 2553394; E-mail: psidhu25@rediffmail.com

Received June 19, 2014; Accepted October 17, 2014; Published October 20 2014

Citation: Sidhu PK, Kaur G, Kumbhar G, Balaje RM, Gupta MP (2014) Optimization of Dosage Regimen of Gentamicin against Pasteurella multocida in Bovines: Old Drug, New Approach. J Veterinar Sci Technol 5: 199. doi:10.4172/21577579.1000199

Copyright: ( 2014 Sidhu PK, et al. This is an open-access article distributed under the terms of the Creative Commons Attribution License, which permits unrestricted use, distribution, and reproduction in any medium, provided the original author and source are credited. 
was developed several decades ago and dosage schedules used for this drug are not based on the modern drug development programs.

Earlier, the dose of antimicrobials was selected so that the plasma concentration of the drug exceeded the minimum inhibitory concentration (MIC) for as long as possible. In the last decades, studies using in vitro and animal models have played a significant role in obtaining a more detailed understanding regarding the relationship between the PK and PD properties of antibacterial agents. Clinical success of antimicrobials have been correlated with bacterial killing using surrogate markers derived from $\mathrm{PK}$ and $\mathrm{PD}$ data employing techniques of PK-PD integration and/or PK-PD modeling [4,6,7]. Recently, determination of PK-PD indices using mutant prevention concentration (MPC) viz., area under serum concentration versus time curve (AUC)/ MPC and peak drug concentration $\left(\mathrm{C}_{\max }\right) / \mathrm{MPC}$ ratio have been proposed to restrict the emergence and enrichment of resistance mutants $[10,11]$. Therefore, there is need for modeling dosing regimens using MPC-based thresholds to restrict emergence of resistance and it requires generation of databases in which MPC is determined for clinical isolates of target pathogen. The study was undertaken to conduct PD, PK-PD integration and PK-PD modeling of the gentamicin data for dose optimization to ensure clinical success and minimization of the selection of mutants with the objectives: (i) to measure the MIC, minimum bactericidal concentration (MBC) and MPC of gentamicin against $P$. multocida; (ii) to determine the timekill kinetics of gentamicin for $P$. multocida over an incubation period of $24 \mathrm{~h}$; (iii) to obtain PK-PD indices by integrating PK-PD data for achieving optimum therapeutic success of gentamicin against HS in buffalo species; (iv) to establish MPC based PK-PD indices predicting the emergence of resistance for gentamicin against $P$. multocida; (v) to design the rational dosage schedule of gentamicin against $P$. multocida in buffalo species using PK-PD modeling approach

\section{Methods}

\section{Drugs and organisms used}

A pure standard of gentamicin was purchased from M.P. Biomedicals India, Pvt. Ltd. Mumbai. A pathogenic strain of P. multocida (P52:B2) was supplied by the Punjab Veterinary Vaccine Institute, Ludhiana, India. Another strain of $P$. multocida (serotype unknown) was obtained from a buffalo suffering from HS. The fresh culture was grown on blood agar (BA) plates by incubating the plates statically at $37^{\circ} \mathrm{C}$.

\section{Determination of $\mathrm{MIC}$ and $\mathrm{MBC}$}

For gentamicin, MIC and MBC were determined in vitro in $\mathrm{MHB}$ and serum of buffalo calves for two isolates of $P$. multocida. MIC and $\mathrm{MBC}$ were determined by Micro-dilution method according to Clinical and Laboratory Standards Institute (CLSI) guidelines [12]. Five overlapping sets of doubling dilutions were used to increase the accuracy. Briefly, nine to ten colonies were used to inoculate $10 \mathrm{~mL}$ of $\mathrm{MHB} /$ serum, followed by incubation at $37^{\circ} \mathrm{C}$ on a shaking incubator $(220 \mathrm{rpm})$ for $5 \mathrm{~h}$ and final cell count were approximately $2-3 \times 10^{8} \mathrm{cfu} /$ $\mathrm{mL}$. A $10 \mu \mathrm{L}\left(\sim 2-3 \times 10^{6} \mathrm{cfu} / \mathrm{mL}\right)$ of this culture was used to inoculate each well of multiwell plate having broth or serum samples with known concentrations of gentamicin. Getamicin solution $(0.20 \mathrm{~mL}$; in $\mathrm{MHB} /$ serum) at twice the required final maximum concentration was added to $0.20 \mathrm{~mL}$ of MHB and serum as described by Sidhu et al. [13]. Bacterial counts expressed as $\mathrm{cfu} / \mathrm{mL}$ were determined by performing spot plate counts on BA plates following serial dilutions in phosphate buffer saline. The serial dilutions of $10^{-2}, 10^{-3}, 10^{-4}, 10^{-5}$ and $10^{-6}$ were prepared. Four $25 \mu \mathrm{L}$ drops of the appropriate dilutions were dropped on the $\mathrm{BA}$ plates, allowed to dry and incubated at $37^{\circ} \mathrm{C}$ for 18 h. Bacterial counts were determined for each $25 \mu \mathrm{L}$ drop and lower limit of quantification was $10 \mathrm{cfu} / \mathrm{mL}$. A MBC was determined in accordance with CLSI guidelines [12] using a single set of doubling dilutions. The MIC well and three other wells with drug concentrations higher than MIC were used to establish MBC using the spot plate count method. The lowest drug concentration which completely inhibits the growth of bacteria on plates after $18 \mathrm{~h}$ incubation was recorded as MBC.

\section{Determination of MPC}

The MPC of gentamicin was determined in MHB following the previously described method by Blondeau and co-workers [11]. Briefly, a natural isolate of $P$. multocida was freshly grown from stocks stored at $-20^{\circ} \mathrm{C}$ for each experiment. A starter culture was prepared by inoculating $400 \mathrm{~mL}$ of MHB with all the single colonies of the strain obtained on $\mathrm{BA}$ plate and then incubating overnight at $37^{\circ} \mathrm{C}$ in static incubator. Next morning, this culture yielded $\sim 1-2 \times 10^{10} \mathrm{cfu} / \mathrm{mL}$. One $\mathrm{ml}$ of this culture was diluted $(1: 10)$ in pre-warmed MHB and put on orbital shaking incubator for $6 \mathrm{~h}$ at $37^{\circ} \mathrm{C}$ to provide an estimated growth of $6-7 \times 10^{10}$ $\mathrm{cfu} / \mathrm{mL}$. A $100 \mu \mathrm{L}$ of this culture was used to inoculate already prepared BA plates having different concentrations of gentamicin and plates were incubated at $37^{\circ} \mathrm{C}$ with $0.1 \%$ carbon dioxide. The drug concentrations used were: $0 \times \mathrm{MIC}, 1 \times \mathrm{MIC}, 2 \times \mathrm{MIC}, 3 \times \mathrm{MIC}, 4 \times \mathrm{MIC}, 5 \times \mathrm{MIC}, 6 \times \mathrm{MIC}$, $8 \times \mathrm{MIC}, 10 \times \mathrm{MIC}, 12 \times \mathrm{MIC}, 16 \times \mathrm{MIC}, 20 \times \mathrm{MIC}, 24 \times \mathrm{MIC}, 32 \times \mathrm{MIC}$, $48 \times \mathrm{MIC}, 64 \times \mathrm{MIC}, 96 \times \mathrm{MIC} \mu \mathrm{g} / \mathrm{mL}$. The plates were incubated for $72 \mathrm{~h}$ and were checked for growth of the pathogens after every $24 \mathrm{~h}$. The MPC was recorded as the lowest multiples of MIC that prevented the growth of bacteria completely at $72 \mathrm{~h}$ of incubation. The each experiment was done in triplicate on different days to take into account the inter-day and intra-day variability. The initial inoculums size of the culture was determined with each experiment by serial dilutions $\left(10^{-2}, 10^{-4}, 10^{-6}, 10\right.$ ${ }^{8}$ ) and spot-plate counts.

\section{Time kill kinetics}

In vitro time-kill curves of gentamicin were established on $\mathrm{MHB}$ and buffalo calf serum as described by Aliabadi and Lees [14]. Briefly, a natural isolate of $P$. multocida was freshly grown from stocks stored at $-20^{\circ} \mathrm{C}$ for each experiment. A starter culture was prepared by inoculating $10 \mathrm{~mL}$ of $\mathrm{MHB}$ with 5-6 colonies of the strain to be tested and then incubating overnight at $37^{\circ} \mathrm{C}$ in an orbital shaking incubator to provide an estimated growth of $1 \times 10^{8} \mathrm{cfu} / \mathrm{mL}$. Fifty $\mu \mathrm{L}$ of this culture were diluted 1:50 in freshly prepared pre-warmed $\mathrm{MHB} /$ serum and incubated statically for $1 \mathrm{~h}$ at $37^{\circ} \mathrm{C}$. The cells were centrifuged at $3100 \mathrm{~g}$ for $2 \mathrm{~min}$. The supernatant was discarded and the cells re-suspended in $50 \mu \mathrm{L}$ phosphate buffered saline. The counts of viable cells $\left(1-2 \times 10^{7} \mathrm{cfu} /\right.$ $\mathrm{mL}$ ) were determined by serial dilution and spot-plate counts. Volumes of $390 \mu \mathrm{L} \mathrm{MHB}$ and serum were pre-warmed in an incubator at $37^{\circ} \mathrm{C}$ and each was inoculated with $10 \mu \mathrm{L}$ of the starter culture to give a final volume of $400 \mu \mathrm{L}$. The cultures were then placed in an orbital shaking incubator at $37^{\circ} \mathrm{C}$. Four drops of $25 \mu \mathrm{L}$ of each culture was sampled and the viable count was determined by serial dilution and spot-plate counts after $0,1,2,5,8,10$ and $24 \mathrm{~h}$ incubation. The lower limit of quantification was $10 \mathrm{cfu} / \mathrm{mL}$.

\section{Determination of PK-PD indices}

The mean values of PK-PD indices correlating bacteriological outcome, $\mathrm{C}_{\max } / \mathrm{MIC}$ and $\mathrm{AUC}_{24 \mathrm{~h}} / \mathrm{MIC}$ were calculated using published PK data of gentamicin in buffalo species [15] for serum against $P$. multocida (Table 2). In addition, PK-PD variables, $\mathrm{C}_{\max } / \mathrm{MPC}$ and $\mathrm{AUC}_{24 \mathrm{~h}} / \mathrm{MPC}$ were calculated to determine the values required to prevent the selection of $P$. multocida mutants against gentamicin. 
Citation: Sidhu PK, Kaur G, Kumbhar G, Balaje RM, Gupta MP (2014) Optimization of Dosage Regimen of Gentamicin against Pasteurella multocida in Bovines: Old Drug, New Approach. J Veterinar Sci Technol 5: 199. doi:10.4172/2157-7579.1000199

\section{PK-PD modeling}

For PK-PD modelling, PD parameters were calculated using the nonlinear Win-Nonlin regression programme (Pharsight Corporation, Mountain View, CA, USA). The $\mathrm{AUC}_{24 \mathrm{~h}} / \mathrm{MIC}$ data from in vitro bacterial growth inhibition curves were modelled to the Sigmoidal E-max equation (1):

$$
\text { Dose }=\frac{C L x\left(\frac{A U C_{24 h}}{M I C}\right) x M I C_{90}}{F}
$$

where $\mathrm{E}_{\mathrm{o}}$ is the change in $\log \mathrm{cfu} / \mathrm{mL}$ of sample (serum) after 24 $\mathrm{h}$ incubation in the control sample (without gentamicin) compared to the initial inoculum $\log \mathrm{cfu} / \mathrm{mL}$, Emax is the maximum antibacterial effect determined as difference in $\log \mathrm{cfu} / \mathrm{mL}$ in samples incubated with gentamicin between time 0 and $24 \mathrm{~h}$ when the detection limit $(10 \mathrm{cfu} /$ $\mathrm{mL}$ ) is reached, $\mathrm{C}_{\mathrm{e}}$ is the $\mathrm{AUC}_{24 \mathrm{~h}} / \mathrm{MIC}$ in the effect compartment (ex vivo site), and $\mathrm{N}$ is the Hill coefficient which describes the steepness of the $\mathrm{AUC}_{24 \mathrm{~h}} / \mathrm{MIC}$-effect curve.

The antibacterial effect of gentamicin was quantified for three levels of growth inhibition by calculation of $\mathrm{AUC}_{24 \mathrm{~h}} / \mathrm{MIC}$ for bacteriostatic action, bactericidal action and bacterial eradication. $\mathrm{AUC}_{24 \mathrm{~h}} / \mathrm{MIC}$ values for bacteriostatic and bactericidal actions were defined as those values which produced $\mathrm{E}=0$ (no change in bacterial count after $24 \mathrm{~h}$ incubation) and $\mathrm{AUC}_{24 \mathrm{~h}} / \mathrm{MIC}=-3$ (a $3 \log$ or $99.9 \%$ reduction of the original inoculum count after $24 \mathrm{~h}$ incubation), respectively. For bacterial eradication $\mathrm{AUC}_{24 \mathrm{~h}} / \mathrm{MIC}$ was defined as the lowest $\mathrm{AUC}_{24 \mathrm{~h}} /$ MIC which provided a 4 log reduction in bacterial count of original inoculums.

\section{Results}

\section{Determination of MIC, MBC and MPC}

The gentamicin MICs, MBCs and MPCs for the two strains of $P$. multocida in Mueller Hinton Broth (MHB) and serum are presented in Table 1. The MICs and MBCs of gentamicin in MHB were not much different than the values obtained in serum. The MBC: MIC ratios ranged from 1.23 to 1.27 for both fluids. The MPC $(\mathrm{MPC}=8 \times \mathrm{MIC})$ was higher than MIC and MBC (Table 1).

\section{In vitro growth inhibition curves}

In vitro growth inhibition curves of gentamicin in MHB and serum against $P$. multocida are illustrated in Figures 1 and 2. Values are mean of two strains, standard error bars are not shown for clarity. The growth inhibition curves were characteristic of a concentration and time-dependent killing action of gentamicin. The bacterial count increased by $>100$-foldsafter $24 \mathrm{~h}$ incubation in control samples. The viable count decreased by $3-\log$ colony forming units $(\mathrm{cfu}) / \mathrm{mL}$ after 2 $\mathrm{h}$ of incubation at $4 \times \mathrm{MIC}$ for isolates of $P$. multocida and reduction of $4-\log \mathrm{cfu} / \mathrm{ml}$ occurred at $5 \mathrm{~h}$ of incubation at 2,4 and $8 \times \mathrm{MIC}$. There was

\begin{tabular}{|l|c|c|c|c|}
\hline Parameter & Matrix & Strain 1 & Strain 2 & Mean \pm SD \\
\hline MIC & MHB & 0.75 & 0.8 & $0.78 \pm 0.02$ \\
\hline & Serum & 0.75 & 0.75 & $0.75 \pm 0.00$ \\
\hline MBC & MHB & 0.9 & 1 & $0.95 \pm 0.05$ \\
\hline & Serum & 0.9 & 1 & $0.95 \pm 0.05$ \\
\hline MBC/MIC & MHB & 1.2 & 1.25 & $1.23 \pm 0.02$ \\
\hline & Serum & 1.2 & 1.33 & $1.27 \pm 0.06$ \\
\hline MPC & MHB & 6 & 6 & $6.00 \pm 0.00$ \\
\hline MPC/MIC & MHB & 8 & 8 & $8.00 \pm 0.00$ \\
\hline
\end{tabular}

MIC: minimum inhibitory concentration; MBC: minimum bactericidal concentration; MPC: mutant prevention concentration.

Table 1: MIC, MBC and MPC $(\mu \mathrm{g} / \mathrm{mL})$ of gentamicin against $P$. multocida $(n=2)$.

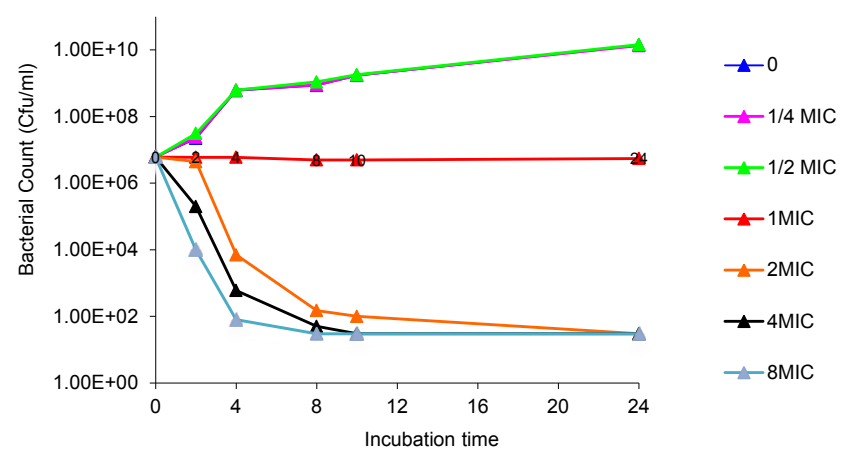

Figure 1: In vitro antibacterial activity of gentamicin in MHB against $P$ multocida $(\mathrm{n}=2)$. SD values are excluded for clarity.

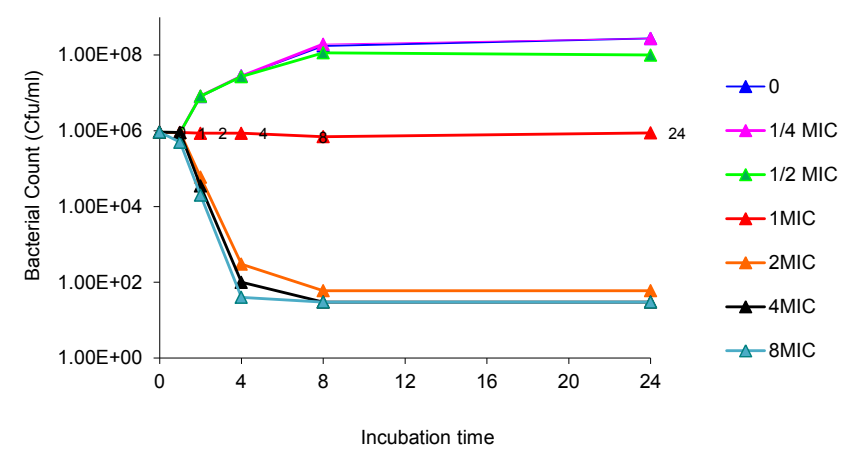

Figure 2: In vitro antibacterial activity of gentamicin in serum of buffalo calves against $P$. multocida $(\mathrm{n}=2)$. SD values are excluded for clarity.

\begin{tabular}{|c|c|c|}
\hline Parameter & Unit & Mean \pm SD \\
\hline $\mathrm{C}_{\max }$ & $\mu \mathrm{g} / \mathrm{mL}$ & $15.89 \pm 0.85$ \\
\hline $\mathrm{AUC}_{\text {0-24h }}$ & $\mu \mathrm{g} \mathrm{h} / \mathrm{mL}$ & $45.90 \pm 0.30$ \\
\hline $\mathrm{MIC}_{\text {(serum) }}$ & $\mu \mathrm{g} / \mathrm{mL}$ & $0.75 \pm 0.00$ \\
\hline $\mathrm{MBC} /$ (serum) & $\mu \mathrm{g} / \mathrm{mL}$ & $0.95 \pm 0.05$ \\
\hline $\mathrm{MPC}$ & $\mu \mathrm{g} / \mathrm{mL}$ & $6.0 \pm 0.00$ \\
\hline $\mathrm{C}_{\max } / \mathrm{MIC}$ & - & $21.00 \pm 0.80$ \\
\hline $\mathrm{AUC}_{0-244} / \mathrm{MIC}$ & $\mathrm{h}$ & $61.00 \pm 0.30$ \\
\hline $\mathrm{C}_{\max } / \mathrm{MBC}$ & - & $17.00 \pm 0.80$ \\
\hline $\mathrm{AUC}_{0-24 \mathrm{~h}} / \mathrm{MBC}$ & $\mathrm{h}$ & $48.00 \pm 0.40$ \\
\hline $\mathrm{C}_{\max } / \mathrm{MPC}$ & - & $2.60 \pm 0.80$ \\
\hline $\mathrm{AUC}_{0-24 \mathrm{~h}} / \mathrm{MPC}$ & $\mathrm{h}$ & $7.62 \pm 0.30$ \\
\hline
\end{tabular}

$\mathrm{C}_{\max }$ : peak concentration; $\mathrm{AUC}$ : area under the curve; $\mathrm{C}_{\operatorname{ma}} / \mathrm{MIC}=$ ratio of in vivo $\mathrm{C}_{\max }^{\max }$ in in vitro MIC; $\mathrm{AUC}_{0-24 \mathrm{~h}}$ /MIC: ratio of in vivo AUC for $24 \mathrm{~h}$ to in vitro MIC; $\mathrm{C}_{\max }$ ' MBC: ratio of in vivo $\mathrm{C}_{\max }$ to in vitro MBC; $\mathrm{AUC}_{0-24} \mathrm{~h} / \mathrm{MBC}$ : ratio of in vivo AUC for

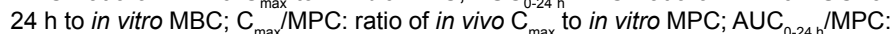
ratio of in vivo AUC $24 \mathrm{~h}$ to in vitro MPC.

*PK data was taken from work of Baxla et al. [20].

Table 2: Integration of *PK-PD data obtained from buffalo calves $(n=5)$ administered with gentamicin by intravenous route $(5 \mathrm{mg} / \mathrm{kg})$.

complete eradication at $8 \mathrm{~h}$ and $24 \mathrm{~h}$ of incubation at concentrations of 4 and $8 \times$ MIC. A high level of kill was attained with $8-24 \mathrm{~h}$ of exposure and the concentration-response relationship was steep. Moreover, there was no re-growth when organisms were exposed to gentamicin concentrations of $8 \times \mathrm{MIC}$ for $8 \mathrm{~h}$ or more.

\section{PK-PD integration}

The PK-PD indices obtained by integrating in vivo $\mathrm{PK}$ data with in vitro $\mathrm{PD}$ data of gentamicin for twod strains of $P$. multocida are 


\begin{tabular}{|l|c|c|}
\hline Parameter & Unit & Mean \pm SD \\
\hline Log $E_{0}$ & $\mathrm{Cfu} / \mathrm{mL}$ & $2.39 \pm 0.09$ \\
\hline Log $\mathrm{E}_{\text {max }}$ & $\mathrm{Cfu} / \mathrm{mL}$ & $-4.51 \pm 0.11$ \\
\hline Log $\mathrm{E}_{\text {max }} \mathrm{E}_{0}$ & $\mathrm{Cfu} / \mathrm{mL}$ & $-6.91 \pm 0.16$ \\
\hline $\mathrm{AUC}_{24 \mathrm{~h}} / \mathrm{MIC}$ for bacteriostatic action & $\mathrm{h}$ & $32.13 \pm 2.05$ \\
\hline $\mathrm{AUC}_{24 \mathrm{~h}} / \mathrm{MIC} \mathrm{EC}_{50}$ & $\mathrm{~h}$ & $36.24 \pm 1.01$ \\
\hline $\mathrm{AUC}_{24 \mathrm{~h}} / \mathrm{MIC}$ for bactericidal action & $\mathrm{h}$ & $47.15 \pm 4.72$ \\
\hline $\mathrm{AUC}_{24 \mathrm{~h}} / \mathrm{MIC}$ for bacterial eradication & $\mathrm{h}$ & $60.96 \pm 3.85$ \\
\hline Slope $\mathrm{N})$ & - & $4.859 \pm 0.71$ \\
\hline
\end{tabular}

$\mathrm{E}_{0}$ : difference in bacterial count in control sample (without drug) between time 0 and $24 \mathrm{~h} ; \mathrm{E}_{\max }$ : difference in bacterial count in sample incubated with gentamicin between time 0 and $24 \mathrm{~h}$, when the detection limit is reached; $\mathrm{AUC}_{24} / \mathrm{MIC} \mathrm{EC}_{50}$ $\mathrm{AUC}_{24 \mathrm{~h}} / \mathrm{MIC}$ of drug producing $50 \%$ of the maximum antibacterial effect; $\mathrm{N}$ : slope of the $\mathrm{AUC}_{24 \mathrm{~h}} / \mathrm{MIC}$ - response curve.

Table 3: PK- PD modeling of gentamicin against $P$. multocida using in vitro serum data in buffalo calves.

given in Table 2. The $\mathrm{C}_{\max } / \mathrm{MIC}$ was 21 ( $\mathrm{MIC}=0.75 \mu \mathrm{g} / \mathrm{mL}$ in $\mathrm{MHB}$ and serum) which exceeded the recommended literature value of 8-10. Another PK-PD indicator, $\mathrm{AUC}_{24 \mathrm{~h}} / \mathrm{MIC}(61 \mathrm{~h})$ for treatment efficacy was below the target of $80 \mathrm{~h}$. The PK-PD indices correlating the risk of emergence of resistance, $\mathrm{AUC}_{24 \mathrm{~h}} / \mathrm{MPC}$ and $\mathrm{C}_{\max } / \mathrm{MPC}$ were $7.62 \mathrm{~h}$ and 2.60 , respectively (Table 2 ).

\section{PK-PD modeling}

PK-PD modelled data for gentamicin are presented in Table 3. The predicted $\mathrm{AUC}_{24 \mathrm{~h}} / \mathrm{MIC}$ values for bacteriostatic, bactericidal and bacterial eradication action were $32.13,47.15$ and $60.96 \mathrm{~h}$, respectively.. Exposure levels were not very high for bactericidal and eradication activity of the drug. The concentration-effect relationship was steep as indicated by the value of Hill-coefficient $(\mathrm{N}=4.89)$. The data indicated that gentamicin requires $1.33,2.0$ and 2.5 multiples of MIC for bacteriostatic, bactericidal and eradication activity (Table 3 ).

\section{Discussion}

\section{PK-PD relationships}

Recently optimal dosage regimens of antimicrobials are redefined as the dosage schedules which not only maximize the clinical efficacy, but also minimize the selection and spread of microbial resistance $[1,16]$. PK-PD indices $\left(\mathrm{C}_{\max } / \mathrm{MIC}, \mathrm{AUC}_{24 \mathrm{~h}} / \mathrm{MIC}\right.$, percentage of dosage interval for which serum drug concentration exceeds MIC, T> MIC) specific to the group of antibiotics have been recommended as predictors of antibiotic efficacy [1,5,17-20]. For aminoglycosides, bacterial eradication is concentration-dependent, and the therapeutic goal is to maximize drug exposure or these agents are most effective when they have a high $\mathrm{C}_{\max } / \mathrm{MIC}$ ratio [16]. The $\mathrm{C}_{\max } / \mathrm{MIC}$ obtained for gentamicin against $P$. multocida was 20 that exceeded the recommended value of 8-10 (Table 2). $\mathrm{AC}_{\max } / \mathrm{MIC}$ ratio (8) of aminoglycosides within the first $24 \mathrm{~h}$ of treatment resulted in around $90 \%$ bacteriological as well as clinical cure $[21,22]$. However, the outcome of antimicrobial therapy depends on a wide range of factors, including disease severity/pathogen load, strain of pathogen and immunocompetence of the patient. Moreover, the killing mechanisms and the amount of drug required may be both 'bug and drug' specific [23]. Therefore, it necessitates that the optimal numerical value of given PK-PD index, such as $\mathrm{C}_{\max } / \mathrm{MIC}$, should ideally be determined for each drug against a target pathogen. The value of $\mathrm{C}_{\max } / \mathrm{MIC}=21$ for $P$. multocida, indicates that the drug should achieve clinical cure against the pathogens having MIC $\leq 0.75 \mu \mathrm{g} / \mathrm{mL}$ when administered at the dose rate of $5 \mathrm{mg}$ $/ \mathrm{kg}$ body weight by intravenous route [15]. The higher value of $\mathrm{C}_{\max } /$
MIC in this study might be due to usage of plasma concentration at zero time $\left(\mathrm{CP}^{0}\right)$ instead of $\mathrm{C}_{\max }$ obtained from previously published study [24]. Nevertheless, gentamicin is likely to achieve $C_{m a x} / M I C=10$ or above when administered by intramuscular route because of its good bioavailability $(\geq 90 \%)[24,25]$. An $\mathrm{AUC}_{24 \mathrm{~h}} / \mathrm{MIC}$ ratio= $61 \mathrm{~h}$ of gentamicin fell below the required value of $80 \mathrm{~h}$ [20]. It has been reported in man and mice that $\mathrm{AUC}_{24 \mathrm{~h}} / \mathrm{MIC}$ ratio correlates with cure when $\mathrm{C}_{\max } / \mathrm{MIC}$ ratio was less than 8 and it doesn't relate well when latter ratio is $\geq 10$ [26]. Accordingly, in current study $\mathrm{C}_{\max } / \mathrm{MIC}$ is considered as a better predictor of the gentamicin efficacy and suggested clinical cure of HS in buffalo calves. The results obtained were in simulation with previous work where therapeutic efficacy of gentamicin correlated better with $\mathrm{C}_{\max } / \mathrm{MIC}$ in patients treated for gram negative bacillary infection $[27,28]$. Low $\mathrm{AUC}_{24 \mathrm{~h}} / \mathrm{MIC}$ of gentamicin should not be considered as having negative impact on the treatment outcome. Human clinical trials had suggested that therapy with aminoglycosides should be aimed to achieve maximum Cmax/MIC to obtain clinical efficacy and preventing the risk of resistance emergence [29].

There is uncertainty about optimal PK-PD indices of aminoglycosides defining their efficacy and propensity to select resistant mutants. Therefore, it is important for aminoglycosides to determine relationship between serum/plasma concentrations, target pathogen sensitivity, therapeutic response and capacity to prevent the emergence of resistance. A MIC, which is used as basis for dosage regimen does not provide information on the time to kill, the time to maximum kill, the log change within a fixed time, or the maximum reduction in viable counts of bacteria [30]. Time kill kinetic studies address this issue by allowing measurement of the antimicrobial effect of drug quantitatively along with time course over an incubation period of $24 \mathrm{~h}$. Brown and Riviere [22] have proposed that maximum aminoglycoside concentrations at the site of infection should be $\geq 8$-10 times the in vitro determined MIC in order to minimize resistance development. In vitro time-kill studies exhibited concentration and time dependent activity of gentamicin against $P$. multocida in MHB and serum of calves. The in vitro time kill data demonstrated virtual eradication of $P$. multocida by gentamicin (reduced colony forming units $(\mathrm{cfu}) / \mathrm{mL}$ to $<10$ ) at concentrations 4 and $8 \times \mathrm{MIC}$. Moreover, a bactericidal level of action ( $3 \log$ reduction in bacterial count) was well maintained up to $24 \mathrm{~h}$ after $2 \mathrm{~h}$ of incubation both in MHB and serum of buffalo calves. There was no re-growth when organisms were exposed to low gentamicin concentrations in vitro. The data generated on time kill kinetics confirmed that the gentamicin is bactericidal against $P$. multocida as described in standard texts for aminoglycosides as a group. Further, there can be marked variations in the killing activity of a single drug against different strains of pathogens belonging to same species and MIC provides no information about it. In fact, strains variation within a bacterial species impact the PK/PD indices, and that such variability needed to be considered when targeting specific therapeutic outcomes [31]. Use of minimum bactericidal concentration (MBC) has been suggested in addition to (or in lieu of) MIC values as a PD parameter to handle the strain differences within the same species of pathogens [32]. The MIC of gentamicin fell within the earlier reported range $(0.03-8 \mu \mathrm{g} /$ $\mathrm{mL})$ against $P$. multocida isolates $(\mathrm{n}=154)$ recovered from cattle suffering from upper respiratory tract infections [33]. The $\mathrm{MIC}_{50}$ and $\mathrm{MIC}_{90}$ of gentamicin determined in this study were 2 and $4 \mu \mathrm{g} / \mathrm{ml}$, respectively. The lower MIC and MBC obtained in the current investigation than previous reported $\mathrm{MIC}_{50}$ indicated the sensitivity of pathogen and utility of gentamicin for the treatment of HS. The clinicians recommend the use of aminoglycosides for treatment in infections associated with pathogens having MIC $\leq 1 \mu \mathrm{g} / \mathrm{ml}$ [34]. Predicted daily doses of gentamicin were calculated using equation 2 (Table 4 ). 


\begin{tabular}{|c|c|c|c|c|}
\hline${ }^{*} \mathbf{M I C}_{90}$ & Bacteriostatic $^{\mathbf{a}}$ & Bactericidal $^{\mathbf{b}}$ & Eradication $^{\mathbf{c}}$ & ${ }^{* *} \mathbf{A U C}_{\mathbf{2 4 h}} \mathbf{}^{\mathbf{M I C}}=\mathbf{8 0}$ \\
\hline 1 & 1 & 1.46 & 1.9 & 2.48 \\
\hline & & & & \\
\hline 2 & 2 & 2.91 & 3.8 & 4.96 \\
\hline 4 & & & & \\
\hline 4 & 4 & 5.82 & 7.6 & 9.92 \\
\hline
\end{tabular}

${ }^{*} \mathrm{MIC}_{90}=$ minimum inhibitory concentration $(\mu \mathrm{g} / \mathrm{mL})$ for $90 \%$ isolates; $\mathrm{AUC}_{24 \mathrm{~h}} / \mathrm{MIC}$ : ratio of in vivo AUC

$\mathrm{a}, \mathrm{b}, \mathrm{c}$ ModelledAUC $/ \mathrm{MIC}$ values for bacteriostatic activity $(32 \mathrm{~h})$, for bactericidal activity (47 h) and for bacterial eradication (4 log inhibition) $=61 \mathrm{~h}$;

${ }^{* *}$ RecommendedAUC ${ }_{24 \mathrm{~h}} / \mathrm{MIC}$ value for clinical efficacy of aminoglycosides.

Table 4: Estimated daily dosage $(\mathrm{mg} / \mathrm{kg})$ of gentamicin for intravenous administration in buffalo calves.

$$
\text { Dose }=\frac{C L x\left(\frac{A U C_{24 h}}{M I C}\right) x M I C_{90}}{F}
$$

Based on a requirement to provide a bactericidal effect, the estimated dose of gentamicin is $2.48 \mathrm{mg} / \mathrm{kg}$ against $P$. multocida in buffalo calves to be repeated after every $24 \mathrm{~h}$, with values of $\mathrm{Cl}, \mathrm{AUC}_{24 \mathrm{~h}} / \mathrm{MIC}$ and $\mathrm{MBC}$ of $0.031 \mathrm{~mL} / \mathrm{kg} / \mathrm{h}, 80 \mathrm{~h}$, and $1.0 \mu \mathrm{g} / \mathrm{mL}$, respectively. In this study $\mathrm{F}$ is not applicable as the drug was administered by intravenous route. The PK-PD relationships suggested that the daily dosage of $2.5 \mathrm{mg} / \mathrm{kg}$ body weight would be able to produce clinical and bacteriological cure in buffalo calves against susceptible pathogens having MIC $\leq 1.0 \mu \mathrm{g} / \mathrm{mL}$.

However, several studies have supported that $\mathrm{C}_{\max } / \mathrm{MIC}$ and $\mathrm{AUC}_{24 \mathrm{~h}} /$ MIC ratios are predictors of therapeutic outcomes but don't correlate well with the resistance emergence of antimicrobials [11,32,35]. Recently, use of MPC based PK-PD indices have been recommended to restrict the emergence and amplification of mutant subpopulation [10,32,35]. During severe infections, the initial inoculums may exist as a mixture of more than one population of microbes having high and low sensitivity to antimicrobials. An overgrowth of a pre-existing subpopulation with an initially lower level of susceptibility may occur due to exposure to antibiotics and resistance may emerge [36,37]. Therefore, a strategy to reduce the size of the Mutant Selection Window (MSW) that covers the concentration range between the MIC of a wild bacterial population and MPC has been proposed by adjusting the dosage regimen [38]. The therapeutic usefulness of MPC is dependent on obtaining its value below the attainable serum and tissue concentrations of drug post administration at doses that are safe for patients [11].

We integrated our in vitro MPC data with published in vivo PK information of gentamicin determined in the buffalo calves. Extrapolating from the in vitro MPC data indicated that in vivo it should be possible to eradicate less susceptible strains of $P$. multocida bearing in mind the MPC $(6.0 \mu \mathrm{g} / \mathrm{mL})$ of gentamicin, although it is possible that mutants could be selected when drug levels in serum/tissues fall in MSW. It seems, eradication of strains that already had some resistance will not be difficult, in view of the higher peak serum concentrations (15 $\mu \mathrm{g} / \mathrm{mL}$ ) of gentamicin in vivo. The $\mathrm{C}_{\max } / \mathrm{MPC}$ and the AUC/MPC ratios were 2.6 and $7.6 \mathrm{~h}$, respectively, for gentamicn against $P$. multocida. The $\mathrm{C}_{\max }$ /MPC ratio is quite small compared to $\mathrm{C}_{\max } / \mathrm{MIC}$ achieved in the study. However, the value of $\mathrm{C}_{\max } / \mathrm{MPC}$ required for prevention of resistance emergence of gentamicin against $P$. multocida is not known and would be point of interest for future studies.

The studies establishing the MPC/MIC ratios of fluoroquinolones have been documented by many research groups but there is limited information for aminoglycosides on this PD parameter [39-41]. A MPC range of $2-512 \mu \mathrm{g} / \mathrm{mL}$ with $\mathrm{MPC}_{50}$ of $44.2 \mu \mathrm{g} / \mathrm{mL}$ against $E$. coli isolates from human patients have been reported for gentamicin in Nigeria [41]. Compared to this study, although the MPC $(6 \mu \mathrm{g} /$ $\mathrm{mL}$ ) of gentamicin was lower but MPC/MIC ratio (8) was higher than the reported value of 2.8 by these authors. Low MPC/MIC ratio obtained in human study is due to the fact that $\mathrm{MIC}_{50}(16 \mu \mathrm{g} / \mathrm{mL})$ was quite high compared to $\mathrm{MIC}=0.75 \mu \mathrm{g} / \mathrm{mL}$ of our data. Moreover, it was not possible for us to determine $\mathrm{MIC}_{50}$ because of small number of isolates. However, gentamicin MPC/MIC ratio (8) obtained by us was exactly the same as determined by Miller and co-authors against E. coli [42]. The limitation for comparing the results is MPC and MIC values are specific to bacterial species. The MPC/MIC ratios reported for ciprofloxacin were; 24 for Mycobacterium smegmatis, 53 for $M$. tuberculosis and 13 for Staphylococcus aureus [39]. To the best of our knowledge, no record of the MPC data of gentamicin for Pasteurella spp. was traced to compare our data. There is need to establish data on MPC of gentamicin for many isolates of different bacterial species and strains to attain useful information for predicting dosage regimens that will restrict the development of resistance in clinical conditions.

\section{PK-PD modeling}

Another approach for predicting efficacy of antimicrobials is use of PK-PD modeling which combines the PK and PD information and describes the time course of antibiotic effect as a function of the drug dosage regimen. The advantage of using PK-PD modeling approach for the selection of dosage regimens of antibiotics to improve the probability of therapeutic success and its potential for minimization of resistance development has been suggested by previous authors $[1,7,17]$. For antimicrobials it has been emphasized that actual ratios required for providing differing levels of growth inhibition for individual drugs acting against specific pathogens should be used as an alternative to using the widely quoted ratios of $\mathrm{C}_{\max } / \mathrm{MIC}$ and $\mathrm{AUC}_{24 \mathrm{~h}} / \mathrm{MIC}[1,13,32]$.

The PK-PD modeling approach was applied to gentamicin against two pathogenic strains of $P$. multocida using PK data from buffalo calves which had received a clinically recommended dose of $5 \mathrm{mg} /$ $\mathrm{kg}$ body weight. Based on exposure over a $24 \mathrm{~h}$ period, $\mathrm{AUC}_{24 \mathrm{~h}} / \mathrm{MIC}$ values required for three levels of growth inhibition, bacteriostatic and 3 or $4 \log$ reductions in bacterial count were determined. The numerically closer values of $\mathrm{AUC}_{24 \mathrm{~h}} / \mathrm{MIC}$ were required to achieve both bacteriostatic and bactericidal activity against $P$. multocida with gentamicin. This supports the existing knowledge and present findings of in vitro time kill kinetics that gentamicin is bactericidal in nature against $P$. multocida. The modelled $\mathrm{AUC}_{24 \mathrm{~h}} / \mathrm{MIC}$ ratios providing a 3 $\log$ and $4 \log$ reductions in bacterial count with gentamicin were $47 \mathrm{~h}$ and $61 \mathrm{~h}$, respectively. PK-PD modeled value of $\mathrm{AUC}_{24 \mathrm{~h}} / \mathrm{MIC}$ (61) for eradication of the test organism was much lower than the widely quoted literature value of $80 \mathrm{~h}-100 \mathrm{~h}$. Based on the relationship; Dose $=\mathrm{Cl} / \mathrm{F}$ $\times \mathrm{AUC}_{24 \mathrm{~h}} / \mathrm{MIC} \times \mathrm{MIC}_{90}$, these data indicate a gentamicin once daily dosage of $1.42 \mathrm{mg} / \mathrm{kg}$ for the strain of organism used in this study (MIC $=0.75 \mu \mathrm{g} / \mathrm{mL})$. In Sri Lanka, Abeynayake et al. [43] reported that all the P. multocida isolates obtained from buffalo and cows suffering from Pasteurellosis were sensitive to gentamicin at the concentration of $1 \mu \mathrm{g} / \mathrm{mL}$. Therefore, $1 \mu \mathrm{g} / \mathrm{mL}$ was taken as $\mathrm{MIC}_{90}$ of gentamicin for dosage determination, as $\mathrm{MIC}_{90}$ data of gentamicin against $P$. Multocida is not available in buffalo species. The corresponding estimated dose for gentamicin by taking literature value of $\mathrm{MIC}_{90}(1 \mu \mathrm{g} / \mathrm{mL})$ would be $1.90 \mathrm{mg} / \mathrm{kg}$. In broader sense, the calculated dose $(2.48 \mathrm{mg} / \mathrm{kg})$ of gentamicin based on literature recommended value of $\mathrm{AUC}_{24} / \mathrm{MIC}$ for aminoglycosides is very near to the dose $(1.90 \mathrm{mg} / \mathrm{kg})$ calculated by using PK-PD modelled values of $\mathrm{AUC}_{24 \mathrm{~h}} / \mathrm{MIC}$. This validates the use of PK-PD modeling approach as a basis for optimization of gentamicin 
dosage for its clinical use against Pasteurellosis. The minor discrepancy in the dose might be due to the fact that literature quoted value of $\mathrm{AUC}_{24 \mathrm{~h}} / \mathrm{MIC}$ had been established either in laboratory animals or human patients but not in bovines or other species of farm animals. There is a need to determine these values in the target species to achieve maximum accuracy and efficacy of dose regimens of antimicrobials. The gentamicin estimated dose by taking literature $\mathrm{MIC}_{90}=4 \mu \mathrm{g} / \mathrm{mL}$ would be $7.56 \mathrm{mg} / \mathrm{kg}$ using PK-PD modeled $\mathrm{AUC}_{24 \mathrm{~h}} / \mathrm{MIC}$ value of 61 $\mathrm{h}$ [33]. Overall, the present findings support the use of low dose of $2-2.5 \mathrm{mg} / \mathrm{kg}$ of gentamicin in buffalo species for achieving optimum clinical and bacteriological cure for Pasteurellosis and may help in reducing the risk of development of toxicity. This is the first report in buffalo species where PK-PD modeling approach along with mutant selective window (MSW) concept is used for dosage optimization of gentamicin. Nevertheless, the MIC of antimicrobials is influenced by the inoculum size, or the size of the bacterial population used for its determination. Our MIC data for gentamicin pertains to $4-6 \times 10^{6} \mathrm{cfu} /$ $\mathrm{mL}$ inoculums size of $P$. multocida. In acute infections, inoculums are usually of $\geq 1 \times 10^{8} \mathrm{cfu} / \mathrm{mL}$, MIC may be escalated in such situations. Hence the higher dose may be required to treat severe infections. Therefore, determination of MICs of antimicrobials with varying levels of inoculums size of pathogens would be our future research interest.

\section{Conclusions}

It is concluded that the MPC measurements along with MIC values of gentamicin allowed us to define the MSW for P. multocida in buffalo calves. Taking into consideration MPC values of gentamicin along with PK-PD indices it seems that likelihood for selection of resistant mutants will be minimal at the dose rate of $2.5 \mathrm{mg} / \mathrm{kg}$ in buffalo calves. However, further studies are warranted to establish in vitro MIC and MPC data for large number of P. multocida isolates to generate $\mathrm{MIC}_{90}$ and $\mathrm{MPC}_{90}$ data that will be useful in optimizing the dosage regimens for prevention of resistant emergence. Using PK-PD modeling and integration, it is suggested that gentamicin at the dose rate of $2-2.5 \mathrm{mg} /$ $\mathrm{kg}$ would be effective in treating infections in buffalo calves caused by $P$. multocida with $\mathrm{MIC}_{90}$ of $\leq 1.0 \mu \mathrm{g} / \mathrm{mL}$. However, in worst clinical infections associated with $P$. multocida of $\mathrm{MIC}_{90} \geq 4.0 \mu \mathrm{g} / \mathrm{mL}$, a higher dose at the rate of $7.5 \mathrm{mg} / \mathrm{kg}$ is recommended.

\section{Competing Interests}

There are no competing interests.

\section{Acknowledgements}

A RKVY grant supported this work. Help rendered by Dr. H.M. Saxena, Professor and Head, Veterinary Microbiology, GADVASU is highly acknowledged.

\section{Authors Contributions}

PKS was the team leader in designing and executing the study and wrote the manuscript. G Kaur, G Kumbhar and BRM performed the laboratory work, analyzed the data for the PK-PD modeling and assisted in writing. MPG provided valuable expert advice in designing the experiments, provided laboratory facilities to conduct this work and assisted in writing.

\section{References}

1. Toutain PL, del Castillo JR, Bousquet-Mélou A (2002) The pharmacokineticpharmacodynamic approach to a rational dosage regimen for antibiotics. Res Vet Sci 73: 105-114.

2. Sahm DF, Brown NP, Draghi DC, Evangelista AT, Yee YC, et al. (2008) Tracking resistance among bacterial respiratory tract pathogens: summary of findings of the TRUST Surveillance Initiative, 2001-2005. Postgrad Med 120: 8-15.

3. Samtani MN, Flamm R, Kaniga K, Nandy P (2010) Pharmacokineticpharmacodynamic-model-guided doripenem dosing in critically ill patients. Antimicrob Agents Chemother 54: 2360-2364.
4. Lees P, Aliabadi FS, Toutain PL (2004) PK-PD modeling: an alternative to dose titration studies for antimicrobial drug dosage selection. Journal of Regulatory Affairs 15: 175-180.

5. Nielsen El, Cars O, Friberg LE (2011) Pharmacokinetic/pharmacodynamic (PK/PD) indices of antibiotics predicted by a semimechanistic PKPD model: a step toward model-based dose optimization. Antimicrob Agents Chemother 55: 4619-4630.

6. Toutain PL (2003) Antibiotic treatment of animals-a different approach to rational dosing. Vet J 165: 98-100.

7. Toutain PL, Lees $P$ (2004) Integration and modelling of pharmacokinetic and pharmacodynamic data to optimize dosage regimens in veterinary medicine. $J$ Vet Pharmacol Ther 27: 467-477.

8. De Alwis MC (1992) Haemorrhagic septicaemia--a general review. Br Vet J 148: 99-112.

9. Benkirane A, De Alwis MCL (2002) Haemorrhagic septicaemia, its significance, prevention and control in Asia. Vet Med Czechoslovakia 47: 234-240.

10. Olofsson SK, Marcusson LL, Lindgren PK, Hughes D, Cars O (2006) Selection of ciprofloxacin resistance in Escherichia coli in an in vitro kinetic model resistance between drug exposure and mutant prevention concentration. J Antimicrob Chemother 57: 1116-1121.

11. Blondeau JM, Zhao X, Hansen G, Drlica K (2001) Mutant prevention concentrations of fluoroquinolones for clinical isolates of Streptococcus pneumoniae. Antimicrob Agents Chemother 45: 433-438.

12. Nicolau DP (2003) Optimizing outcomes with antimicrobial therapy through pharmacodynamic profiling. J Infect Chemother 9: 292-296.

13. AliAbadi FS, Lees $P$ (2000) Antibiotic treatment for animals: effect on bacterial population and dosage regimen optimisation. Int J Antimicrob Agents 14: $307-$ 313.

14. Ambrose PG, Grasela DM, Grasela TH, Passarell J, Mayer HB, et al. (2001) Pharmacodynamics of fluoroquinolones against Streptococcus pneumoniae in patients with community-acquired respiratory tract infections. Antimicrob Agents Chemother 45: 2793-2797.

15. Craig WA (1998) Pharmacokinetic/pharmacodynamic parameters: rationale for antibacterial dosing of mice and men. Clin Infect Dis 26: 1-10.

16. Turnidge J (2003) Pharmacodynamics and dosing of aminoglycosides. Infect Dis Clin North Am 17: 503-528, v.

17. Jacobs MR (2001) Optimisation of antimicrobial therapy using pharmacokinetic and pharmacodynamic parameters. Clin Microbiol Infect 7: 589-596.

18. Brown SA, Riviere JE (1991) Comparative pharmacokinetics of aminoglycoside antibiotics. J Vet Pharmacol Ther 14: 1-35.

19. Lees P, Concordet D, Aliabadi FS, Toutain PL (2006) Drug selection and optimization of dosage schedules to minimize antimicrobial resistance. In Antimicrobial Resistance in Bacteria of Animal Origin, Aarestrup, Frank M (Ed.). ASM Press, Washington, DC, Pp. 49-71.

20. Baxla SL, Kumar M, Jayachandran C, Roy BK, Kumari A (2010) Pharmacokinetics of Gentamicin and its Interaction with Paracetamol after i.v. Administration in Buffalo Calves (Bubalus bubalis). J Bioanal Biomed 2: 65-68.

21. Abo El Sooud K (2003) Comparative disposition kinetics and plasma protein binding of gentamicin sulphate in three juvenile animal species. J Vet Med $A$ Physiol Pathol Clin Med 50: 196-200.

22. Bailey DN, Briggs JR (2004) Gentamicin and tobramycin binding to human serum in vitro. J Anal Toxicol 28: 187-189.

23. White DG, Ayers S, Maurer JJ, Thayer SG, Hofacre C (2003) Antimicrobia susceptibilities of Staphylococcus aureus isolated from commercial broilers in northeastern Georgia. Avian Dis 47: 203-210.

24. Moore RD, Lietman PS, Smith CR (1987) Clinical response to aminoglycoside therapy: importance of the ratio of peak concentration to minimal inhibitory concentration. J Infect Dis 155: 93-99.

25. Kashuba AD, Nafziger AN, Drusano GL, Bertino JS Jr (1999) Optimizing aminoglycoside therapy for nosocomial pneumonia caused by gram-negative bacteria. Antimicrob Agents Chemother 43: 623-629.

26. Nicolau DP, Freeman CD, Belliveau PP, Nightingale CH, Ross JW, et al. (1995) Experience with a once-daily aminoglycoside program administered to 2,184 adult patients. Antimicrob Agents Chemother 39: 650-655. 
Citation: Sidhu PK, Kaur G, Kumbhar G, Balaje RM, Gupta MP (2014) Optimization of Dosage Regimen of Gentamicin against Pasteurella multocida in Bovines: Old Drug, New Approach. J Veterinar Sci Technol 5: 199. doi:10.4172/2157-7579.1000199

27. MacGowan A, Bowker K (2002) Developments in PK/PD: optimising efficacy and prevention of resistance. A critical review of PK/PD in in vitro models. Int $J$ Antimicrob Agents 19: 291-298.

28. Liang B, Bai N, Cai Y, Wang R, Drlica K, et al. (2011) Mutant prevention concentration-based pharmacokinetic/pharmacodynamic indices as dosing targets for suppressing the enrichment of levofloxacin-resistant subpopulations of Staphylococcus aureus. Antimicrob Agents Chemother 55: 2409-2412.

29. Martinez MN, Papich MG, Drusano GL (2012) Dosing regimen matters: the importance of early intervention and rapid attainment of the pharmacokinetic pharmacodynamic target. Antimicrob Agents Chemother 56: 2795-2805.

30. Schwarz S, Kehrenberg C, Salmon SA, Watts JL (2004) In vitro activities of spectinomycin and comparator agents against Pasteurella multocida and Mannheimia haemolytica from respiratory tract infections of cattle. J Antimicrob Chemother 53: 379-382.

31. Barza M, loannidis JP, Cappelleri JC, Lau J (1996) Single or multiple daily doses of aminoglycosides: a meta-analysis. BMJ 312: 338-345.

32. Zhao X, Drlica K (2008) A unified anti-mutant dosing strategy. J Antimicrob Chemother 62: 434-436.

33. Schentag JJ (1999) Pharmacokinetic and pharmacodynamic surrogate markers: studies with fluoroquinolones in patients. Am J Health Syst Pharm 56: S21-24.

34. Olofsson SK, Cars O (2007) Optimizing drug exposure to minimize selection of antibiotic resistance. Clin Infect Dis 45 Suppl 2: S129-136.

35. Zhao X, Drlica K (2001) Restricting the selection of antibiotic-resistant mutants: a general strategy derived from fluoroquinolone studies. Clin Infect Dis 33 Suppl 3: S147-156
36. Drlica K (2003) The mutant selection window and antimicrobial resistance. J Antimicrob Chemother 52: 11-17.

37. Linde HJ, Lehn N (2004) Mutant prevention concentration of nalidixic acid ciprofloxacin, clinafloxacin, levofloxacin, norfloxacin, ofloxacin, sparfloxacin or trovafloxacin for Escherichia coli under different growth conditions. J Antimicrob Chemother 53: 252-257.

38. Ngwai YB, Shekwodza CA, Istifanus $\mathrm{H}$, Nkene IH, Owuna GE, et al. (2013) Mutant Prevention Concentrations of Some Aminoglycoside Antibiotics fo Fecal Isolates of Escherichia coli under different Growth Temperatures. J Natural Sci Res 3: 147-155.

39. Miller K, O’Neill AJ, Chopra I (2004) Escherichia coli mutators present an enhanced risk for emergence of antibiotic resistance during urinary tract infections. Antimicrob Agents Chemother 48: 23-29.

40. Sidhu PK, Landoni MF, Aliabadi FS, Lees P (2010) PK-PD integration and modeling of marbofloxacin in sheep. Res Vet Sci 88: 134-141.

41. Abeynayake P, Wijewardana TG, Thalagoda SA (2010) Antimicrobial susceptibility of $P$. multocida isolates: Pasteurellosis in production animals-Part 6: 193-196.

42. Clinical and Laboratory Standards Institute (2008) Performance standards for antimicrobial disk and dilution susceptibility tests for bacteria isolated from animals; approved standard third edition. CLSI document, M31-A3, Wayne, PA

43. Aliabadi FS, Lees P (2002) Pharmacokinetics and pharmacokinetic pharmacodynamic integration of marbofloxacin in calf serum, exudate and transudate. J Vet Pharmacol Ther 25: 161-174. 